\title{
A nutricionalização da vida na tela da TV
}

\section{Jeferson Bertolini}

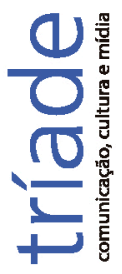

Universidade Estadual de Ponta Grossa, Programa de Mestrado em Jornalismo, Ponta Grossa, Paraná, Brasil. Contato com o autor: jefersonbertolini@gmail

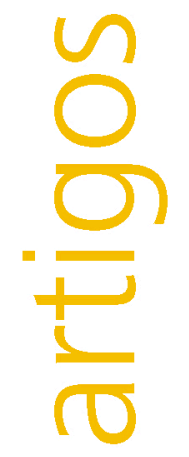


Resumo: Este artigo apresenta resultados de pesquisa sobre a participação de nutricionistas em programas de TV sobre saúde e bem-estar. O objetivo é mostrar como os nutricionistas são apresentados nesses televisivos e como o público (entendido aqui como um conjunto aleatório de indivíduos expostos a esses programas de maneira direta ou indireta) percebe a figura do nutricionista. Este trabalho analisa a questão pela ótica do biopoder (forma indireta de governar a vida que busca aumentar as potencialidades físicas da população para produzir corpos economicamente ativos). O trabalho usa análise de conteúdo, observação participante e questionários. O manuscrito conclui que a TV, ao dar visibilidade aos nutricionistas, colabora com o projeto do biopoder de construir corpos economicamente ativos, e efetiva a nutricionalização da vida.

Palavras-chave: Televisão. Nutrição. Biopoder.

Abstract: This article presents some research results about the participation of nutritionists in TV programs. Its goal is to show how nutritionists are presented on these television shows and how the public (understood here as a random set of individuals exposed to these programs both in a direct and an indirect way) perceives the nutritionist's figure. (Aqui, deu-se preferência à construção com o possessive, porque a construção com of é mais recomendada quando se trata de pessoas eminentes, como por exemplo: The wife of the President). This paper analyzes the question from the perspective of biopower (indirect way of living rule which seeks to increase the physical potentialities of the population to produce economically active bodies). The work applies content analysis, participant observation and questionnaires. The manuscript concludes that TV, by giving visibility to nutritionists, collaborates with the biopower project to build economically active bodies and effective nutritiousness of living.

Keywords: Television, Nutrition. Biopower. 


\section{Introdução}

Este artigo apresenta resultados de uma pesquisa sobre a participação de nutricionistas em programas de TV sobre saúde e bem-estar. Procura-se saber: (a) como os nutricionistas são apresentados nesses televisivos e (b) como o público, entendido aqui como um conjunto aleatório de indivíduos expostos a esses programas de maneira direta ou indireta, percebe a figura do nutricionista.

No Brasil, a saúde ganhou espaço em programas de TV em 2000, quando o médico Drauzio Varella iniciou parceria com o dominical Fantástico, da Rede Globo, apresentando a série Viagem ao corpo humano. A aceitação foi tamanha que, em 2011, a emissora criou um programa diário para tratar do tema, o Bem Estar.

Este trabalho analisa a participação de nutricionistas em programas de TV pela ótica do biopoder. Trata-se da forma indireta de governar a vida, iniciada no século 17, que busca aumentar as potencialidades físicas da população para produzir corpos economicamente ativos. O biopoder divide-se em dois eixos: disciplina (governo dos corpos dos indivíduos) e biopolítica (governo da população como um todo). Com o biopoder, o poder de morte converteu-se no complemento de um poder que se exerce positivamente sobre a vida, interferindo em sua gestão, majoração e multiplicação. "Transformou-se no exercício, sobre a vida, de controles precisos e de regulações de conjunto" (FOUCAULT, 2012, p. 151).

$\mathrm{Na}$ análise deste autor, a medicina é uma operadora do biopoder porque, desde o século 17, encarregou-se de processos que buscavam curar doenças que afligiam a população. Usando um viés crítico, ocupou-se de processos que causavam a subtração das forças e a diminuição do tempo de trabalho da população.

Na perspectiva deste estudo, a nutrição tem exercido papel parecido com o da medicina: o nutricionista aparece como profissional encarregado de regular a alimentação da população; faz isso sob o pretexto da saúde, mas acaba por colaborar com o projeto do biopoder de construir corpos ativos.

Para este trabalho, programas de TV sobre saúde e bem-estar colaboram com esta regulação coletiva da alimentação porque, cada vez mais, têm dado espaço aos nutricionistas e valorizado o conhecimento desses profissionais.

Este trabalho procura apontar o que diz a TV sobre a nutrição, por isso usa análise de conteúdo, e anotar o que diz o público sobre a nutrição por meio da observação participante em supermercado e academia de ginástica, locais onde se pensa a saúde pela alimentação e pela atividade física, e faz consulta com questionários.

O objetivo destas técnicas não é se aproximar de um estudo de audiência. Não se procura apurar se o que é dito pela TV influencia o público. Apenas se observa no público a mesma categoria analisada na TV.

Este trabalho não busca medir a influência da mídia. Entretanto, parte do pressuposto de que, mesmo as camadas da população não expostas à mídia de maneira direta, sejam tocadas de 
maneira indireta por ela, via amigos, família etc. Afinal, "os processos de comunicação sofrem a influência dos meios de comunicação de massa, seja de modo direto, seja em maior escala através dos líderes de opinião" (HABERMAS, 1978, p. 197).

Este é um estudo interdisciplinar. Associa temas da Filosofia e de outras ciências humanas à Comunicação Social. A interdisciplinaridade "não é um método novo; é uma estratégia eficiente para a compreensão, interpretação e explicação de temas complexos" (MINAYO, 2010, p. 441). É "um conceito que invocamos sempre que nos defrontamos com um problema cujo princípio de solução exige o consumo de múltiplas e diferentes perspectivas" (POMBO, 2007, p. 7).

O texto está dividido em seis seções. A primeira detalha a metodologia do estudo. A segunda apresenta o programa Bem Estar, escolhido por ser o primeiro da TV brasileira sobre saúde e bem-estar e por ser apresentado diariamente na maior emissora do Brasil. A terceira apresenta os campos da observação participante. A quarta traz frases extraídas da análise de conteúdo do programa Bem Estar. A quinta apresenta frases extraídas de conversas com pessoas durante observação participante (representam o que aqui é chamado de público). A sexta traz as respostas via questionários.

\section{Metodologia}

Este estudo cruza três técnicas de pesquisa: análise de conteúdo (para apurar o que diz a mídia sobre nutrição), observação participante em supermercado e academia de ginástica (para apurar a percepção do público sobre nutrição) e consulta com questionários (para complementar a percepção do público sobre nutrição).

A análise de conteúdo foi aplicada ao programa Bem Estar, da Rede Globo, o primeiro da TV brasileira sobre saúde e bem-estar. Foram analisados 81 programas (33,19\% dos exibidos em 2016).

Este estudo adota o modelo de análise de conteúdo proposto por Bardin (2010). "A análise de conteúdo é um conjunto de instrumentos metodológicos que se aplica a discursos extremamente diversificados. Ela absolve e cauciona o investigador pela atração pelo escondido, o latente, o não aparente" (BARDIN, 2010, p. 7).

Seguindo o modelo da autora, este trabalho fez uma leitura flutuante de 22 programas Bem Estar de 2015 antes da definição do objeto de estudo; definiu o corpus com base em critérios de representatividade (primeiro mês de cada estação do ano); escolheu temas (temas podem ser palavras ou frases sobre o assunto pesquisado) como unidade de contexto e programas (81 analisados) como unidade de registro; e definiu as categorias de análise com base no critério semântico (reúne temas afins na mesma categoria).

A observação participante em supermercado e academia foi feita na Grande Florianópolis. Trata-se da região mais populosa de Santa Catarina, o Estado reconhecido pelos índices de qualidade de vida. O supermercado foi encolhido porque é o local onde as pessoas compram 
o que vai alimentar a família. A academia foi escolhida por ser um dos locais onde as pessoas treinam o corpo. Os dois estabelecimentos são frequentados por todos os tipos de classe social, embora seja possível notar certo predomínio da classe média.

No supermercado, a observação foi feita em visitas diárias, cada uma de 45 minutos, durante 90 dias, em 2016. Elas resultaram em 320 "situações" observadas (situações englobam diálogos entre pesquisador e pesquisado e diálogos entre pesquisados). O procedimento adotado foram conversas com clientes: o autor deste trabalho, no papel de um consumidor comum, conversou com clientes sobre as expectativas deles em relação aos produtos; por que escolheram os itens que estavam na cesta; quais produtos gostariam de levar e não levaram etc. As conversas foram sempre no contexto da vida saudável, com foco em alimentação. Não descambaram para cuidados estéticos e produtos de beleza. Algumas duraram poucos minutos. Outras, quase uma hora.

$\mathrm{Na}$ academia, a observação também foi feita durante três meses, em 2016. Foram 78 visitas, cada uma com duração entre 45 e 75 minutos. Elas resultaram em 250 "situações" observadas. Matriculado como aluno regular, o autor deste estudo treinou com outros alunos, de diferentes idades e classes sociais, durante o período analisado, procurando saber o que pensam sobre saúde, alimentação, cuidado com o corpo, vaidade, disciplina e afins. As conversas também envolveram instrutores e sócios da academia. As visitas ocorreram em turnos alternados, para abraçar diferentes tipos de público (de manhã há um predomínio de donas de casa; à noite há presença maior de jovens que procuram ter mais músculo).

A observação participante é uma técnica etnográfica, sendo frequentemente equiparada à etnografia (RESTREPO, 2010, p. 12). Esta técnica consiste no contato direto do pesquisador com o fenômeno observado, para obter informações sobre a realidade dos atores sociais em seu próprio contexto. "A ideia é que, mediante sua presença, o pesquisador pode observar e registrar, de uma posição privilegiada, como as coisas são feitas, quem as realizam, como e onde". "Ser testemunha do que as pessoas fazem permite ao pesquisador compreender, em primeira mão, dimensões fundamentais daquilo que lhe interessa da vida social" (RESTREPO, 2010, p. 12).

A consulta por questionários ouviu 130 pessoas de diferentes idades, raças, sexos, níveis de escolaridade e classe social. Os formulários foram distribuídos pela (a) internet e (b) pessoalmente. O objetivo foi complementar a observação participante em supermercado e academia (para ter medição "estatística" sobre temas observados em campo).

Pela internet, o link do formulário foi distribuído aleatoriamente, por mensagens diretas, via Facebook, a pessoas que comentaram, curtiram ou foram marcadas em postagens do programa Bem Estar. Foram enviadas 400 mensagens. Não foi pedido o nome e a cidade do participante. Ao todo, 65 pessoas responderam aos formulários online.

Pessoalmente, o formulário foi entregue no formato impresso a 100 membros de grupos que se reúnem para fazer atividade física em Santa Catarina; ou que se reúnem em estabelecimentos do Estado, como escolas e igrejas, para participar de palestras sobre temas ligados à 
saúde. Dos formulários impressos, foram selecionadas as primeiras 65 respostas (para igualar ao número dos formulários via internet).

Tanto pela internet quanto pessoalmente, a quantidade de questionários distribuídos não é representativa de nenhum grupo específico e de nenhuma proporção da população brasileira ou catarinense. Trata-se de uma amostra por acessibilidade, na qual "o pesquisador seleciona os elementos a que tem acesso, admitindo que estes possam, de alguma forma, representar o universo" (GIL, 1995, p. 97).

Das 130 pessoas que responderam aos questionários, 80 (61,53\%) declararam "assistir" ao Bem Estar. As 50 demais (38,46\%) disseram "não assistir" ao programa. A amostra ouvida não é representativa da audiência do programa. Também não é possível afirmar se as diferenças nas respostas dos dois grupos ocorrem porque o respondente "assiste" ao programa ou se ocorre o oposto (o respondente "assiste" ao programa porque pensa e age de tal modo). Ainda assim, este estudo considera relevantes as diferenças nas respostas. Por isso, optou por fazer uma leitura separada e comparativa entre os respondentes que "assistem" e que "não assistem" ao Bem Estar.

A principal vantagem dos questionários é o fato de "os informantes poderem se sentir mais seguros em função de seu caráter anônimo e, com isso, se sentirem mais à vontade para expressar pontos de vista que temam colocá-los em situação problemática ou que julguem não ter aprovação" (SELLTIZ; WRIGHTSMAN; COOK, 1987, p. 17).

\section{O programa Bem Estar}

O programa Bem Estar é o primeiro da televisão brasileira sobre saúde. Foi criado em fevereiro de 2011 pela Rede Globo, a maior emissora do país. É apresentado de segunda à sexta-feira, ao vivo, entre $10 \mathrm{~h}$ e $10 \mathrm{~h} 45$, com o argumento de "ajudar o público a levar uma vida mais saudável".

O programa está na grade de produtos jornalísticos da emissora. É apresentado por dois jornalistas, que adotam a sobriedade do jornalismo ou a informalidade do entretenimento, de acordo com o tema em destaque. Eles contam com a participação de sete médicos consultores (pediatra, psiquiatra, ginecologista, dermatologista, oftalmologista, cardiologista e ortopedista), que participam ao vivo, em sistema de revezamento, de acordo com a pauta.

Além desses sete médicos, o programa escala outros profissionais da saúde, como fisioterapeutas, nutricionistas, farmacêuticos e outros médicos, para fazerem o papel de consultores. Entre titulares e convidados, ao menos dois deles participam a cada dia como "especialistas". Todos usam jalecos brancos com nome bordado e se tratam por "doutor". Os não médicos convidados a falar ao vivo, como pesquisadores de alimentos, também adotam o jaleco branco.

Em linhas gerais, a atração procura ensinar os segredos da alimentação saudável e a importância da atividade física. Costuma condenar a gordura e incentivar a magreza, apresentada como garantidora da boa saúde. 
O estúdio costuma imitar a sobriedade de um consultório médico, pintado em tom pastel e adornado com livros, maquetes médicas, tubos de ensaio e folhagens discretas. Mas pode reproduzir um ambiente de praia ou de piscina, com espreguiçadeira e guarda-sol, se o tema for ligado ao verão.

O material usado na composição destes ambientes não costuma ser cenográfico. Assim, a mesa da cozinha tem frutas frescas e potes de castanhas, se o assunto exigir; e os consultores e apresentadores podem se servir. Aliás, é comum vê-los provando algum alimento saudável, como suco de couve ou um talo qualquer.

O surgimento do Bem Estar se deu após o sucesso de quadros sobre saúde lançados pela Rede Globo em outros programas jornalísticos da emissora. O mais notório deles foi a participação do médico Drauzio Varella no Fantástico, a partir do ano 2000, quando ele apresentou a série Viagem ao corpo humano

Em 2018, o Bem Estar atingia, segundo a emissora, 5,8 milhões de telespectadores por dia. A audiência era formada por $68 \%$ de mulheres e $32 \%$ de homens. A maioria era da classe C (47\%). Os demais eram das classes A e D (35\%) e E (18\%). A distribuição do público por faixa etária era: de quatro a 11 anos (4\%), de 12 a 17 (6\%), de 18 a 24 (7\%), de 25 a 49 (42\%), maiores de $50(41 \%)$.

\section{Campos observados}

O supermercado escolhido fica na Grande Florianópolis, a região mais urbanizada de Santa Catarina, com 1,5 milhão de habitantes. Santa Catarina foi escolhida por ser o Estado com a maior longevidade do Brasil, o que indica um cuidado dos habitantes com o corpo.

Em linhas gerais, o supermercado atende majoritariamente pessoas da classe média. É frequentado por moradores de toda a Grande Florianópolis por abrigar em suas instalações, além de supermercado, casa lotérica, praça de alimentação, pet shop, salão de beleza, banca, chaveiro, relojoeiro, loja de celulares, loja de instrumentos musicais, gráfica e floricultura.

A academia escolhida é uma das mais tradicionais da Grande Florianópolis. Foi criada nos anos 1980. Tornou-se referência pela regularidade do negócio e pelas modalidades de treino, como musculação, natação, ginástica, bike indoor, dança aeróbica e artes marciais: são 26 modalidades de treino.

A variedade de modalidades dá à academia um corpo de alunos com biotipos, idades e expectativas diferentes em relação ao treino: há quem queira emagrecer, ganhar massa muscular, melhorar o condicionamento físico, definir o corpo, aliviar o estresse, perder gordura localizada, praticar arte marcial etc. A unidade pesquisada tem um fluxo médio de 500 alunos por dia, com elevação no verão. O público majoritário é de classe média. 


\section{O nutricionista no Bem Estar}

No programa, o nutricionista aparece como aquele que detém o conhecimento sobre a alimentação, sabendo tirar o máximo proveito dos alimentos: "A cenoura é antioxidante e anti-inflamatória. É bom para o coração", diz nutricionista ao ensinar a fazer "macarrão de mentira" por trocar massa de farinha por tiras de abobrinha (11/01, sobre macarrão); “Tomate previne câncer" (11/01); "Beterraba combate a pressão alta" (11/01); "Frutas vermelhas são ricas em licopeno, que previnem o câncer de pele" (04/04, sobre frutas).

O nutricionista surge como aquele que ajuda: "Para fazer aquele cocô de dar orgulho na gente, aquele que a gente fica feliz, anota aí uma misturinha que ajuda: aveia, água e fruta" (11/04, sobre prisão de ventre); “Alimentos com triptofano (aveia, batata doce e feijão) ajudam a dormir melhor" (18/01, sobre comer à noite).

Ao apresentar-se como autoridade em alimentos, o nutricionista ganha autoridade $e$ passa a dizer o que está certo ou errado e o que pode ou não pode na hora de comer. "Está certíssimo", diz nutricionista à telespectadora que mandou foto de prato de macarrão com azeite e castanha (11/01, sobre macarrão); "Pode comer sem culpa", diz nutricionista sobre molho de tomate (11/01, sobre macarrão).

Autorizado a opinar, o profissional da nutrição passa a regular o prato alheio. "A meta do dia é comer três porções de frutas" (04/04, sobre frutas); "A dose ideal são duas conchas, senão engorda, ok?", diz nutricionista ao ensinar sopa "para comer sem engordar" (01/07, sobre lanches); "Se você tiver um pudim de leite condensado você vai abrir e fechar a geladeira até ele acabar. Coloque frutas picadas na frente", diz nutricionista ao ensinar a organizar a geladeira para "não cair em tentação" (04/07, sobre trabalho que engorda).

A exemplo do médico, o nutricionista parece crer que é responsável pela saúde da população: "Nós que trabalhamos com saúde pública temos que nos atentar com a prevenção. A gordura abdominal pode ser vista a olho nu", diz nutricionista ao ver, e reprovar, imagem de pessoa acima do peso (25/07, sobre IMC).

O reflexo do poder do nutricionista pode ser observado no programa, entre personagens de reportagem e telespectadores, que fazem perguntas e enviam fotos pela internet. "Eu sabotei uma vez [a dieta]. A nutricionista disse que eu não poderia comer [espetinho de frango] pela forma como ele era preparado [frito], mas eu comi”, diz mulher que pretende perder $40 \mathrm{~kg}$ (24/10, sobre intolerância à lactose).

\section{O nutricionista na percepção do público}

A observação mostra que o nutricionista, que frequentemente aparece nos programas de televisão vestindo jaleco branco, pode ser confundido com um médico: "Eu achava que nutricionista era o mesmo que médico", diz mulher, madura, que comprava pasta de amendoim para passar no pão. "Foi a nutricionista que me mandou comer isso", diz ela sobre o doce que 
promete alimentar com baixo índice calórico e alto índice de gordura boa; "Eu nunca tinha ido no nutricionista. Fui depois do infarto. Gostei. Estou comendo o que ela mandou e já me sinto bem melhor", diz cliente de supermercado, cardíaca e levemente obesa, que reformou a dieta da família após a consulta; "No começo eu estranhei um pouco. Era muita coisa que não podia comer. Mas com a tempo a gente se acostuma", diz homem maduro que frequenta academia e decidiu equilibrar atividade física e alimentação saudável; "Uma amiga foi [à nutricionista] e me indicou. Fui e gostei também. Mas ela é bem pingo no i. Tem que fazer tudo bem direitinho", diz cliente de supermercado, maduro e diabético.

$\mathrm{Na}$ maioria dos casos, as recomendações envolvem evitar alimentos que contenham farinha branca, açúcar, gordura industrializada, gordura animal e sal, e incluir no cardápio o máximo possível de frutas e verduras, preferencialmente cruas, porque assim aumentam a saciedade. Neste contexto, o nutricionista é aquele que indica a melhor forma de preparo dos alimentos, a frequência que devem ser consumidos ao longo do dia ou da semana e as quantidades que devem ser consumidas. "De manhã, eu posso comer banana ou abacate ou goiaba; ao meio dia, como arroz integral e chia; à noite, a comida é normal, mas em menor quantidade", diz cliente de supermercado que foi à nutricionista depois que a tia teve um AVC; "Batata doce pode. Batata inglesa, não. Frango tem que ser sem pele. Fruta é à vontade”, diz mulher que se matriculou na academia para "perder uns quilos" e fez consulta com a nutricionista que atende novos alunos; "Ela [nutricionista] disse para eu evitar pão branco e leite integral. Cortou carne vermelha. Peixe pode abusar. Peixe de água profunda é melhor", relata homem adulto, ligeiramente acima do peso, que também se consultou com nutricionista da academia.

Boa parte dos observados costuma se encantar com os resultados. Por isso passa a recomendar o nutricionista aos amigos, formando um círculo crescente. "Eu tinha muita mancha na pele. Agora, cuidando bem da comida, está clareando tudo", relata mulher adulta, cliente de supermercado, que após a consulta inseriu permanentemente em seu cardápio folhas verdes; "Eu estou menos inchada. Sinto que tudo melhorou, até na hora de ir ao banheiro", conta amiga da cliente do supermercado; "Eu gostei muito. Se tu fores, irás gostar também”, diz homem, aluno de academia, que diz ter emagrecido $10 \mathrm{~kg}$ em dois meses após adotar dieta restrita casada com atividade física.

Apresentado na televisão como aquele que conhece os segredos da alimentação saudável, que sabe extrair o máximo de eficiência dos alimentos e que pode nos ajudar a atingir ou a manter a saúde, o nutricionista passa a dizer o que pode e o que não pode: "A gente quer, mas não pode", diz jovem aluna de academia à amiga que ofereceu pão de queijo na saída do treino. "Minha nutricionista não me deixa comer queijo amarelo", justifica; "A cara está ótima. Mas leva farinha branca, e eu estou cortando farinha branca. Minha nutricionista disse que farinha branca entope a gente", diz mulher adulta e magra à atendente da padaria do supermercado que lhe ofereceu sonho de leite Ninho; "Não posso. Minha nutricionista me mata se eu comer isso", diz aluna de academia a ambulante que lhe ofereceu trufas na saída do treino.

O que é dito pelo nutricionista interfere em grandes decisões, como adotar uma dieta 
para perder até $40 \%$ do peso, ou pequenas escolhas do dia a dia, como a compra de adoçante. "Minha nutricionista diz que este é o melhor que tem", diz mulher de pele bem cuidada sobre produto à base de sacarose que custa $\mathrm{R} \$ 17$, seis vezes mais que o adoçante comum; "Troquei o açúcar branco pelo mascavo. É mais saudável", diz cliente de supermercado; "Não uso mais sal comum. Estou levando o sal marinho", diz dona de casa; "Margarina comum não entra mais lá em casa. Só levo a Becel", diz cliente de supermercado, justificando que o produto indicado pela nutricionista "não entope as veias".

A importância do nutricionista chega a tal ponto que seu receituário pode ser visto até em placas de produtos de supermercado. No estabelecimento observado, as placas com os nomes das frutas trazem "dica de nutrição". A batata doce, por exemplo, "é boa para o bom funcionamento do intestino". A cebola "é antioxidante". A cenoura tem "betacaroteno". A beterraba "tem ferro". "Faz bastante tempo [que as placas foram colocadas]. Só não tem no ovo, mas o ovo todo mundo sabe que faz bem", diz o atendente do setor de frutas.

$\mathrm{Na}$ academia observada, alunos têm desconto na consulta com nutricionista. A profissional atende uma vez por semana na academia. Passa dieta de acordo com os objetivos de cada um. Os professores estimulam as consultas porque "isso dá mais eficiência ao treino". "Todo mundo que faz gosta. Ela [nutricionista] indica uma dieta boa pra ti, pro teu corpo, para aquilo que tu queres [objetivo na academia]", diz sócio de academia.

Embora entre os observados pareça haver uma concordância ou aceitação ao poder nutricional, nota-se uma espécie de frustração por parte daqueles que não podem comprar os alimentos sugeridos pelos nutricionistas ou que não têm tempo para preparar os alimentos da maneira que indicam: "Dizem [o nutricionistas] que comer salmão faz bem. Vai comprar pra ver o preço", diz homem adulto que frequenta academia; "A única coisa barata que eles [nutricionistas] recomendam é mato. O resto, estas frutas secas, estas castanhas, é tudo caro. Não é qualquer um que poder comprar não, meu amigo", diz cliente de supermercado que procurava azeite de oliva para temperar a salada; “A gente até sabe o que é bom comer. Mas não dá para cumprir os horários", diz jovem para amigas na saída da academia. "A vida da gente não casa com o que ela pede", responde uma delas.

\section{As respostas por questionários}

Esta seção apresenta o que pensam os respondentes sobre nutricionismo. As respostas são seguidas de uma leitura/análise dos dados.

O nutricionista é um profissional muito ouvido na TV. Qual o seu grau de confiança neles? (muito baixo; baixo; médio; alto; muito alto). 
Gráfico1: Grau de confiança nos nutricionistas

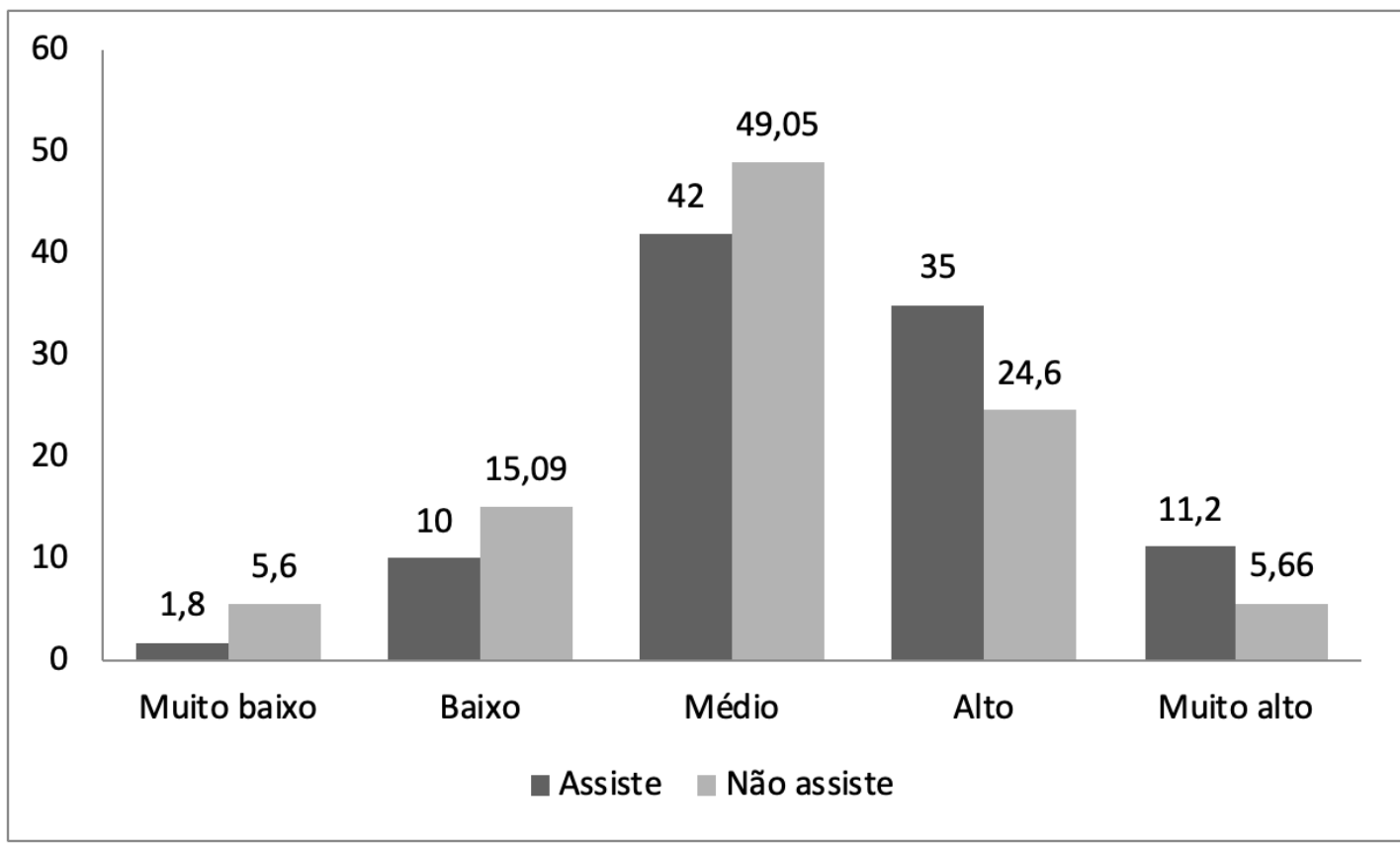

Fonte: Elaboração própria com base nos questionários

No comparativo, chama atenção a diferença entre os participantes que responderam "alto", "muito alto" e "baixo". Entre os que "assistem" ao Bem Estar, 35\% responderam "alto", contra $24,6 \%$ dos que "não assistem" ao programa. No primeiro grupo, 11,2\% responderam "muito alto", contra apenas 5,66\% do segundo grupo. Entre os que "assistem", 10\% responderam "baixo", contra 15,09\% dos que "não assistem".

Leitura possível 1: no plano geral, os respondentes demonstram confiança no nutricionista, profissional que se apresenta como conhecedor dos segredos da boa alimentação, indispensável à obtenção da saúde. Na televisão, o nutricionista tem status de quase médico. No âmbito do biopoder, aparece como figura de destaque na fabricação de corpos economicamente ativos, especialmente quando se percebe a popularização da ideia que diz que "a saúde começa pela boca".

Leitura possível 2: os respondentes que "assistem" ao programa Bem Estar confiam mais no nutricionista, profissional mais entrevistado na atração depois dos médicos. Isso permite supor que a exposição a este profissional, pelas dicas que fornece ou pelo conhecimento que demonstra ter, faz aumentar o grau de confiança. No momento em que a saúde torna-se tema de programa de televisão e que a nutrição se converte em alicerce desse tipo de programa, o nutricionista ganha visibilidade. Ele fala ao grande público, ajudando a inserir uma noção de cuidado pessoal nas massas.

Considerando o preço dos alimentos e o tempo necessário para prepará-los de forma "saudável" (ex. grelhar a carne em vez de fritá-la), como você classifica as dicas dos nutricionistas? (muito difícil de seguir; difícil; moderado; fácil de seguir; muito fácil). 
Gráfico 2: Como os respondentes classificam as "dicas" dos nutricionistas

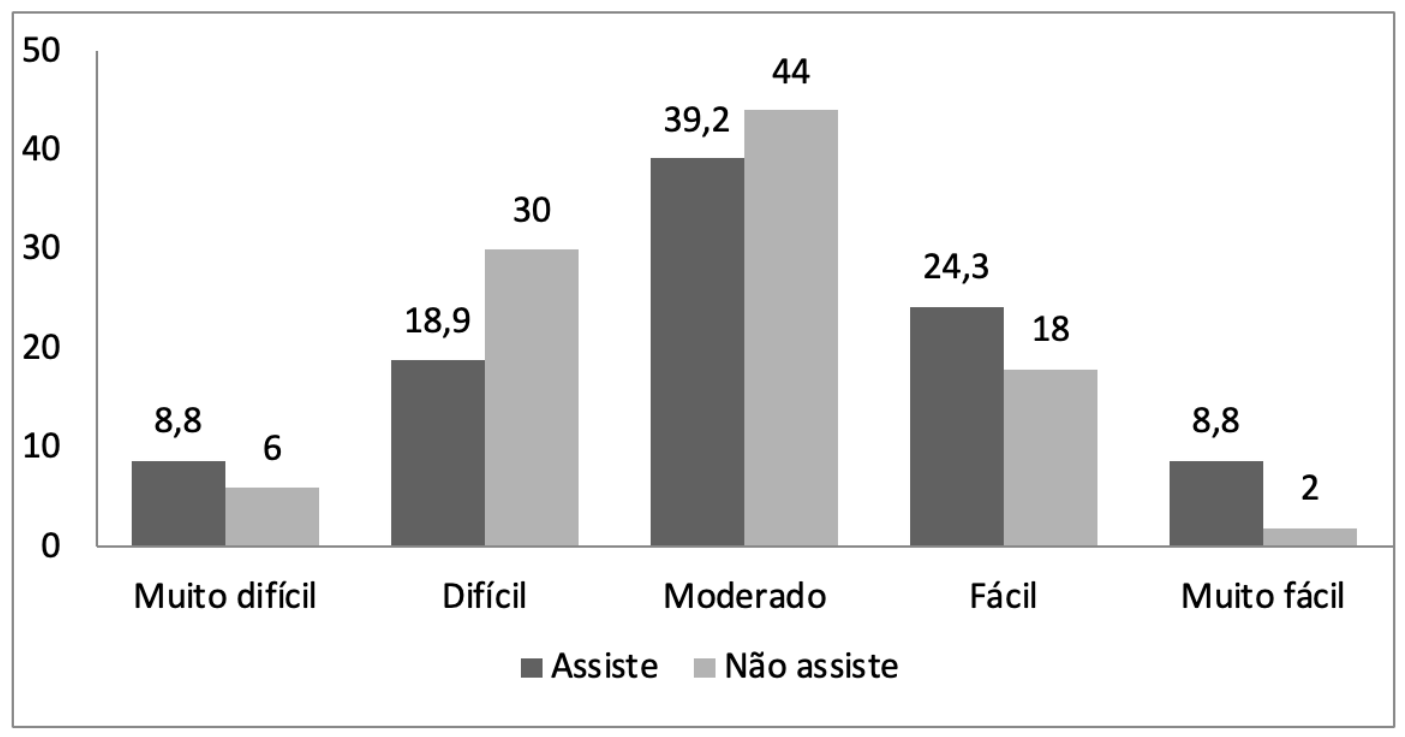

Fonte: Elaboração própria com base nos questionários

No comparativo, o que chama a atenção é a diferença entre os que consideram "fácil", "muito fácil" e "difícil". Entre os que "assistem" ao Bem Estar, 24,5\% responderam "fácil", $8,8 \%$ responderam "muito fácil" e 18,9\% responderam "difícil”. Entre os que "não assistem" ao programa, os percentuais respectivos foram $18 \%, 2 \%$ e $30 \%$.

Leitura possível 1: as respostas sugerem que, de modo geral, a maioria dos respondentes considera aceitáveis (o termo usado foi moderado) as dicas de alimentos e formas de preparo fornecidas pelos nutricionistas. Em parte, isso pode se dever a uma noção ampliada de saúde entre a população (em alguma medida, pela inserção deste tema na mídia) e a um cuidado (seria controle?) governamental sobre saúde (no país, há uma série de leis que regula a indústria da alimentação, com controle de produtos como açúcar e sal; também há leis estaduais, de acordo com realidades locais: no Espírito Santo, para citar um caso, foi criada uma lei que proíbe a disponibilização de saches de sal em mesas de restaurante; em Santa Catarina, para citar outro caso, é proibida a venda de refrigerantes e guloseimas em cantinas de escolas da rede pública).

Leitura possível 2: os respondentes que "assistem" ao Bem Estar parecem ter menos resistência a alimentos "saudáveis", como grãos e farinhas integrais, e a formas de preparo mais trabalhosas, como cozinhar a vapor. Esses alimentos e essas formas de preparo são indicadas pelos nutricionistas porque "aumentam a longevidade e a qualidade de vida". Trata-se de um cenário compatível com o ideal biopolítico. Em parte, essa menor resistência pode se dever à repetição da mensagem (de tanto ser dita na televisão, acaba sendo incorporada pela audiência como modelo normal) ou à aplicabilidade dela (os que provam esses alimentos e essas formas de preparo podem ficar satisfeitos e não ver dificuldades em seu uso). 


\section{Considerações finais}

O profissional de nutrição ganha espaço na TV porque, embora se saiba há séculos que a saúde começa pela boca e que somos o que comemos, a alimentação se converteu em tópico de grande notabilidade no contexto da saúde e bem-estar.

No momento em que a alimentação se converte em tema explorado ao vivo na TV, o nutricionista ganha status de quase médico: se e quando instrumentalizado pelo Estado, esse profissional passa a atuar nas políticas públicas de saúde, sobretudo as que envolvem a política de alimentos, como o controle da obesidade e de outras doenças relacionadas aos hábitos alimentares, como colesterol e AVC.

Para este trabalho, o poder nutricional é compatível com o biopoder porque segue a mesma cartilha do poder medical: o nutricionista, a exemplo do médico, pode se converter em instrumento do controle político para disciplinar a saúde da população; ele serve, por exemplo, à produtividade fabril.

O poder nutricional, como o poder medical, pode transitar entre mecanismos biopolíticos e disciplinares, que juntos formam o biopoder. Isso ocorre porque a alimentação pode estar, ao mesmo tempo, a serviço da saúde da população (biopolítica) como na disciplina alimentar do cidadão (disciplina).

Importante lembrar que o poder medical é elemento clássico do biopoder: a medicina foi o primeiro elo entre política e corpo; à medicina cabia determinar formas e normas pelas quais o corpo politizado seria constituído; a medicina deveria buscar curar doenças que afligiam a população, que causavam a subtração das forças, a diminuição do tempo de trabalho e os custos econômicos pela produção não realizada e pelo tratamento feito.

Neste contexto, a nutricionalização da vida pode ser pensada como uma espécie de departamento da medicalização da vida. A medicalização é um fenômeno através do qual a vida cotidiana é apropriada pela medicina e interfere na construção de conceitos, costumes e comportamentos sociais (CAPONI, 2010).

A participação em programas de TV dá visibilidade ao nutricionista e parece ampliar a preocupação do público com a alimentação, vista como caminho à boa saúde. A alimentação é fonte de preocupação porque "o que comemos se converte em nós mesmos" (FISCHLER, 1995, p. 11) e porque "a alimentação é, após a respiração e a ingestão de água, a mais básica das necessidades humanas" (CARNEIRO, 2003, p. 1).

A TV, ao dar espaço ao nutricionista e a valorizar o conhecimento desse profissional, acaba colaborando com o projeto do biopoder de construir corpos economicamente ativos. Isso pode ocorrer da seguinte maneira: primeiro, a TV dá status ao nutricionista, tornando-o um profissional mais conhecido e respeitado por seus conhecimentos técnicos sobre a alimentação (o poder de influência da mídia ajuda nesta etapa); depois, a TV leva esse conhecimento técnico, traduzido em linguagem fácil do jornalismo, às massas (o público aprende a se alimentar melhor, e como resultado passa a ter um corpo mais resistente ou economicamente ativo). $\mathrm{O}$ 
aprimoramento do corpo é meta do biopoder. Afinal, "o controle da sociedade sobre os indivíduos não se opera simplesmente pela consciência ou pela ideologia, mas começa no corpo, com o corpo". "Foi no biológico, no somático, no corporal que, antes de tudo, investiu a sociedade capitalista" (FOUCAULT, 2012, p. 144).

\section{Referências bibliográficas}

BARDIN, Laurence. Análise de conteúdo. Lisboa: Edições 70, 2010.

CAPONI, Sandra. Medicalização da vida: ética, saúde pública e indústria farmacêutica. Palhoça: Editora Unisul, 2010.

CARNEIRO, Henrique. Comida e sociedade: uma história da alimentação. Rio de Janeiro: Elsevier, 2003.

FISCHLER, Claude. El (h) omnívoro: el gusto, la cocina y el cuerpo. Barcelona: Anagrama, 1995

FOUCAULT, Michel. História da sexualidade I: a vontade de saber. 22. ed. Rio de Janeiro: Graal, 2012.

GIL, Antônio Carlos. Métodos e técnicas de pesquisa social. 4. ed. São Paulo: Atlas, 1995.

HABERMAS, Jüngen. Comunicação, opinião pública e poder. In: COHN, Gabriel. Comunicação e indústria cultural. 4. ed. São Paulo: Cia Editora Nacional, 1978.

MINAYO, Maria Cecília de Souza. Disciplinaridade, Interdisciplinaridade e Complexidade. Revista Emancipação, Ponta Grossa, v. 10, p. 435-442, 2010.

POMBO, Olga. Epistemologia da Interdisciplinaridade. In: Colóquio Interdisciplinaridade, Humanismo e Universidade, número do evento, 2007, Porto. Título...Porto: Cátedra Humanismo Latino, na, pp. Inicial e final. pela Cátedra Humanismo Latino. Porto, 2007.

RESTREPO, Eduardo. Técnicas etnográficas. In: Especialización en Métodos y Técnicas de Investigación en Ciencias Sociales. Fucla, 2010.

SELLTIZ, Claire; WRIGHTSMAN, Lawrence Samuel; COOK, Stuart Wellford. Métodos de pesquisa nas relações sociais. 4. ed. São Paulo: EPU, 1987.

Recebido em: 02/04/2018

Aceito em: 28/11/2018 